\title{
油中造粒におけるオンラインモニタリング
}

\author{
平 島 剛, Winston GUINTO, 恒 川 昌 美* \\ 只野 研 一; 中 島 㦑, 中 村 正 義**
}

\section{On-line Monitoring for Agglomeration in Organic Liquid}

by

Tsuyoshi HIRAJIMA ${ }^{\dagger}$, Winston GUINTO ${ }^{\dagger}$, Masami TSUNEKAWA ${ }^{\dagger}$, Kenichi TADANO $^{\dagger}$, Iwao NAKAJIMA ${ }^{\dagger}$ and Masayoshi NAKAMURA ${ }^{\dagger \dagger}$

In the process of agglomeration in an organic liquid distinct noises are emitted when agglomerates impinge on the walls of the agglomeration vessel. In addition, the turbidity of the suspension changes from opaque to transparent during the progress of agglomeration. On-line monitoring for agglomeration in an organic liquid was investigated by measuring the agglomeration noises and the turbidity of the suspension by laser attenuation.

The relative energy of the noises emitted during the process of agglomeration was shown to be a function of agglomerate diameter and recovery. Recovery was correlated with the amount of attenuation of the laser beam in the suspension. From these results, the technical feasibility of on-line monitoring of the agglomerate's diameter and recovery was demonstrated by measuring relative energy and laser attenuation.

Key Words : On-line Monitoring, Agglomeration in Liquid, Agglomeration Noise, Relative Energy, Laser Attenuation

\section{1. 緒言}

液中造粒法は, 非溶解性架橋液体を添加した微粒子 眯濁液を擋拌することにより，凝集粒子を生成する技 術である。本法では, 適正な造粒条件を与えることに よって懸濁微粒子を液中で凝集, 王密して緻密な造粒 体を形成することができ，低含液率産物の生成，選択 的造粒, 球形造粒体の形成等も可能である。したがっ て, 本法は選鉱, 選炭, 水処理, 七ラミックス製造, 医薬品製造など多くの分野で注目されている。なお，

平成 3 年 12 月 16 日受付

$*$ 北海道大学工学部資源開発工学科

(干 060札帽市北区北13条西 8 丁目) TEL 011-716-2111 内線 6315

***昭和シエル石油 (株) 開発部

(厂100千代田区霞が関3-2-5霞が関ビル) TEL 03-3503-4372

$\dagger$ Dept. of Mineral Res. Dev. Eng., Fac. of Eng., Hokkaido

Univ., Kita 13, Nishi 8, Sapporol 060

$\dagger+$ Showa Shell Sekiyu K.K., 3-2-5

Kasumigaseki, Chiyoda-ku, Tokyo, 100
液中造粒では，懸濁媒が水の場合には水中造粒，有機 溶媒の場合には油中造粒と呼んで区別している。

著者らは，先に ${ }^{1-4)}$ 従来法では製造困難であった500 $\mu \mathrm{m}$ 径以下のジルコニア高強度微小球形体の製造が, 油中造粒法および水中造粒法を用いることにより可能 であることを報告した。ただし，このよらな微小球形 造粒体を目的通りに得るためには，造粒体の形成，成 長あるいは破壊などの経時変化をオンラインでモニタ リングし，目的とした造粒産物が形成された時点で造 粒を終了させる必要がある。従来，液中造粒では，擋 拌消費電力や擋拌トルクの変動 4 , 5) 測定し, これらに よって造粒終点を決定していた。しかし，擋拌消費電 力や擋拌トルクの変動によって, 造粒産物の回収率, 造粒体径をオンラインで管理することは困難である。 液中造粒過程に拈いて造粒体は造粒容器内壁々衝突 しており, 造粒容器はその衝撃力により振動し, 周囲 に音を放射する。ただし，多数の粒子の衝突が重なっ て起こるためそれらの波形は, 単発的なものではなく, 
連続的なノイズとなる。この衝突ノイズは，造粒体の 数, 粒度拈よび密度等に関する情報を含んでいると推 察される。また，造粒体の形成に伴い懸濁液の濁度が 変化するが，この濁度変化より造粒体の量を推定でき る。

本研究では，この観点から造粒過程で発生する/イ ズおよび懸濁液の濁度を示すレーザ光減衰量を計測し, これらの計測結果に基づいてオンラインで造粒体の回 収率，造粒体径をモニタリングする方法について検討 した。

\section{2. 試料および実験方法}

試料として2. $6 \mathrm{~mol} \% \mathrm{Y}_{2} \mathrm{O}_{3}$ を含声ジルコニア粉末（密 度 $5699 \mathrm{~kg} / \mathrm{m}^{3}$ ) を使用した。本試料の粒度分布は, RosinRammler-Bennetの式で表され，その粒度特性值は $0.635 \mu \mathrm{m}$ ，粒度分布指数は 1.075 ，重量 $50 \%$ 粒子径は $0.45 \mu \mathrm{m}$ である。懸濁媒体としてパラフィン系有機液 体 (密度 $750 \mathrm{~kg} / \mathrm{m}^{3}$, 油水界面張力 $0.043 \mathrm{~N} / \mathrm{m}$ ), 架橋液体 として蒸留水を用いた。

Fig. 1 亿半連続式横型造粒装置，ノイズ和よびレー ザ光減衰量の計測装置の概略を示す。造粒実験に当た っては，まず，ジルコニア試料 $100 \mathrm{~g}$ と有機液体 $3200 \mathrm{~cm}^{3}$ を造粒容器内に入れ，インペラーを1840rpm で10秒間 回転させて試料の分散を行った。なお，循環パイプの

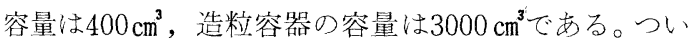
で，所定量の架橋液体を添加した後インペラーを1840 $\mathrm{rpm}$ で所定時間回転させだ。懸濁液は，インペラーの 回転により容器中央部の循環パイプから容器両端部一 循環するようになっている。実験中，造粒過程で発生 するノイズの規模と頻度に関するパラィータおよび循環 パイプ内を流れている懸濁液のレーザ光減衰量 $\alpha$ を計測 した。造粒実験終了後，オイルポンプを起動させ造粒 装置内の産物を取り出し，容器内を洗浄した。造粒実 験は，上記操作を繰り返すことによって進めた。

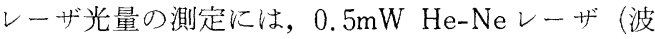

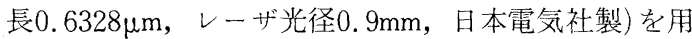
いた。レーザ光減衰量 $\alpha$ は, 次式れよって求めた。

$$
\alpha=-10 \log \left(I / I_{o}\right)
$$

ここに，Iは懸濁液を透過した後のレーザ光量， $I_{0}$ は粒子が懸濁していない有機液体を透過した後の光量 である。

一方，ノイズの規模と頻度に関するパラィ一タは以 下のよらにして計測した。造粒容器外側のフランジ部 分に取り付けた広带域センサー $(100 \mathrm{kHz} \sim 2 \mathrm{MHz} \pm$ $10 \mathrm{~dB}, \mathrm{NF}$ 社製 $\mathrm{AE}-900 \mathrm{~S}-\mathrm{WB})$ によって検出した信 号をプリアンプで増幅後, $100 \mathrm{kHz}$ のハイパスフィル ターにより低周波成分を除去し，さらに，メインアン プで増幅した。信号処理に当たっては半波整流して直 流成分を出力させ，この出力を粒了群の衝突弶ルギー の規模を表すパラメータとした。実際には，Fig. 2 に 示すように直流成分は著しく脈動するために，包絡線

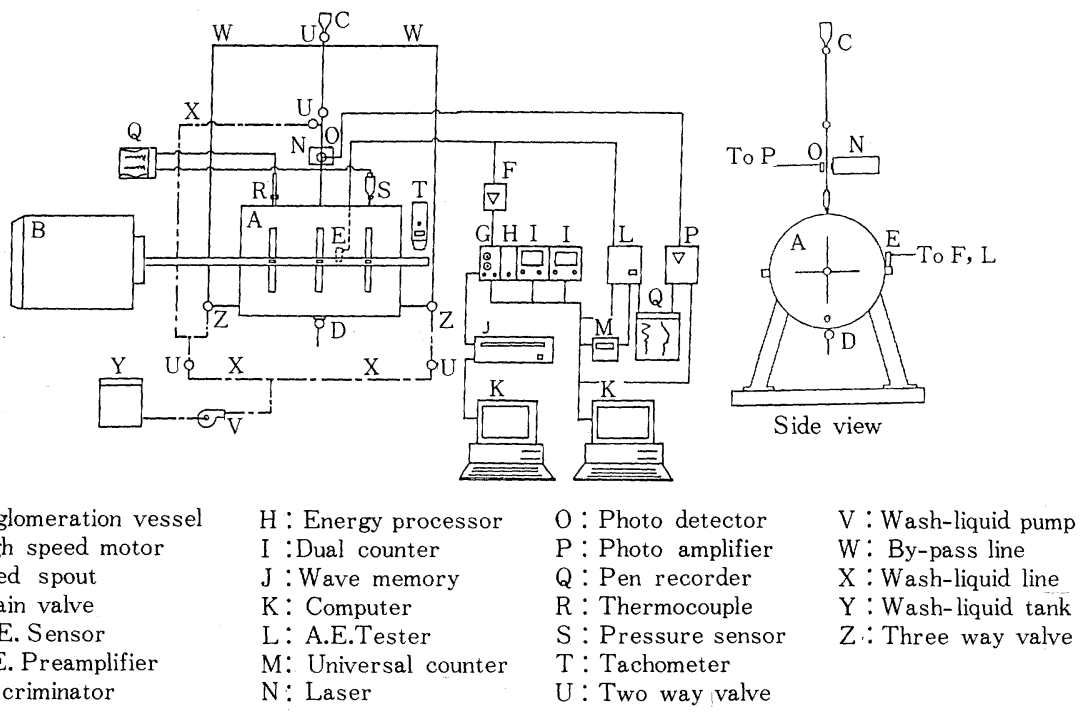

Fig. 1 Semi-continuous agglomeration system with on-line monitoring devices

*著者らは，別報のにて液中造粒に括ける造粒体の圧密過程と成長過程との関係を報告しており，そこでの解析法を適用しインぺ ラー回転速度を1840 rpmに設定した。 


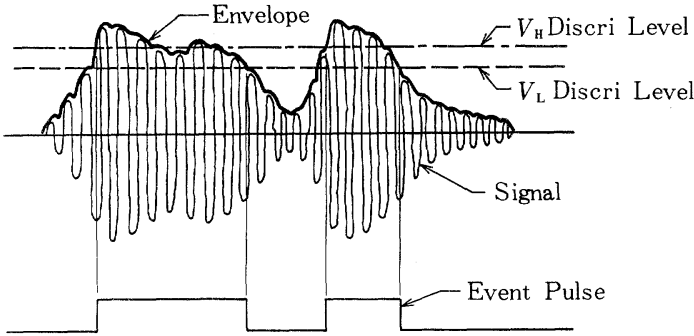

Fig. 2 Signal characterization formats

検波波形を平均化回路で平均化し，その出力と造粒体 平均径との関係について検討した。以下，本文ではこ の平均化した出力を相対エネルギーと呼ぶこととする。 イベント発生率は，Fig. 2 亿示すように包絡線検波波形 をもとに2 弁別レベル方式でイベントパルス変換して 計数した。本実験では， $V_{\mathrm{H}}$ を $3.5 \mathrm{~V} ， V_{\mathrm{L}}$ を $3.4 \mathrm{~V}$ 亿設定 した。

造粒産物は, 実験終了後, $150 \mathrm{mesh}$ のふるいで湿式 ふるい分计を行い, フィード試料重量に対する +150 mesh産物の重量割合 (百分率)を回収率とした。造粒 体 $(+150$ mesh 産物) の粒度分布之球形度（粒子の最大 長之幅の比) は，画像解析装置 (ニレコ社ルーゼックス II）を用いて測定した。測定に用いた造粒体は $1450^{\circ} \mathrm{C}$ で 2 時間焼結した後，上記と同様に粒度分布，球形度 を求めた。また，焼結造粒体の密度は，ピクノメータ 法により測定した。

\section{3. 実験結果および考察}

Fig. 3 K，架橋液体添加量を $95,105,115 \mathrm{~cm}^{3} / \mathrm{kg}$ と して油中造粒実験を行った場合の相対ェネルギー，イ ベント発生率および $\alpha$ の代表的な経時変化の計測例を 示す。架橋液体添加量を $115 \mathrm{~cm}^{3} / \mathrm{kg}$ とした場合には, $\alpha$ は造粒開始後徐々に増大し, 10分程度でピークに達 したあと，20分近くになってから急速に0近くまで低 下した。この $\alpha$ の急低下時には，相対ェネルギーとイ ベント発生率も一時的な変動を示している。この $\alpha$ が ほほぼ 0 を示す時点では，循環パイプ内を通過している 試験液は注潘透明になっており，すべての微粒子が造 粒体となったことを示唆している。架橋液体添加量95 $\mathrm{cm}^{3} / \mathrm{kg}$ では， $\alpha$ の低下し始める時間は遅くなっており その低下曲線の傾きも緩やかとなった。相対エネルギ 一, イベント発生率の最大值は, 架橋液体添加量 115 $\mathrm{cm}^{3} / \mathrm{kg}$ に比べより大きな值を示した。また，架橋液体 添加量 $115 \mathrm{~cm}^{3} / \mathrm{kg}$ で $\alpha$ が 0 となる付近で認められだ相 対エネルギー, イベント発生率の一時的な変動は, 認 められなかった。架橋液体添加量 $105 \mathrm{~cm}^{3} / \mathrm{kg}$ では, 相
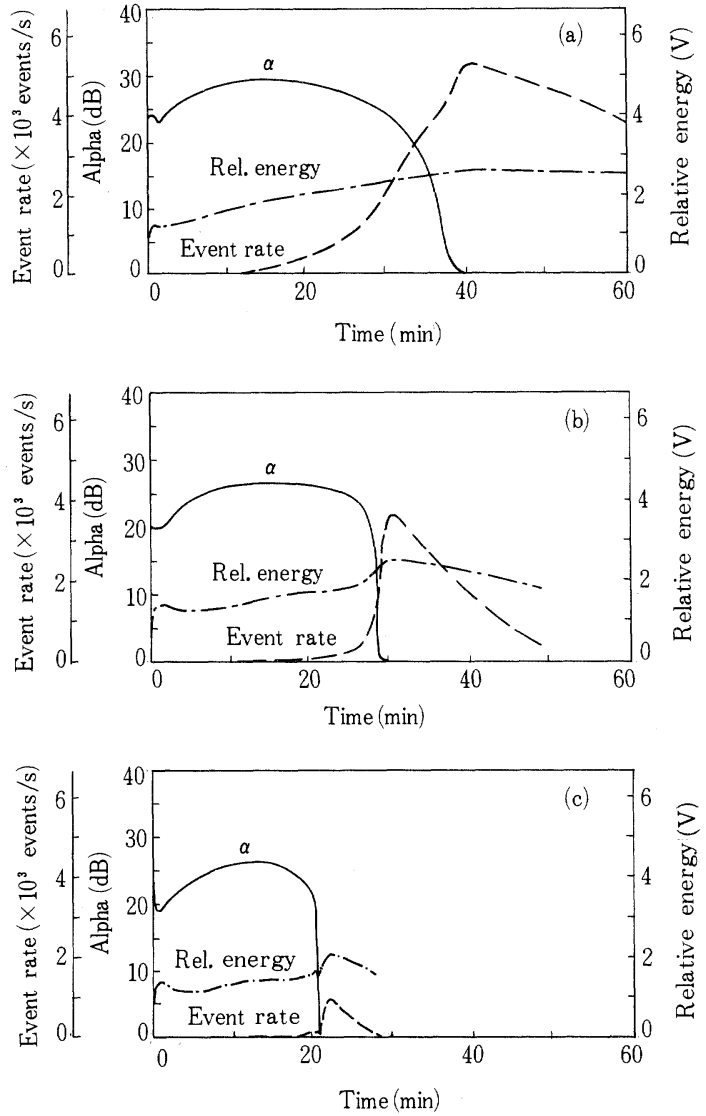

Fig. 3 Variation of $\alpha$, event rate and relative energy with lapse of time for different amounts of bridging liquid : (a) 95 , (b) 105 and (c) $115 \mathrm{~cm}^{3} / \mathrm{kg}$

対エネルギー，イベント発生率， $\alpha$ の変化は，架橋液 体添加量 $95 \mathrm{~cm}^{3} / \mathrm{kg}$ と $115 \mathrm{~cm}^{3} / \mathrm{kg}$ との中間的な傾向を示し た。

Table 1 亿各実験の終了時点で得られた造粒産物の 諸性状值を示す。な扐, 密度については, 焼結造粒体 の密度を示している。架橋液体添加量が少ない汪ど, 造 粒体平均径拈よび標準偏差は小さく, 焼結密度は大き くなった。一般に，造粒開始直後において造粒体の回 収率は低く，造粒体の粒度分布幅は広いが，Fig. 3 で

Table 1 Agglomerate properties for different amounts of bridging liquid

\begin{tabular}{c|c|c|c}
\hline $\begin{array}{c}\text { Bridging liquid } \\
\left(\mathrm{cm}^{3} / \mathrm{kg}\right)\end{array}$ & $\begin{array}{c}\text { Mean diameter } \\
(\mu \mathrm{m})\end{array}$ & $\begin{array}{c}\text { Sphericity } \\
(-)\end{array}$ & $\begin{array}{c}\text { Density** } \\
\left(\mathrm{g} / \mathrm{cm}^{3}\right)\end{array}$ \\
\hline 115 & $682\left(\right.$ s.d. $\left.^{*}=94\right)$ & 1.07 & 5.95 \\
105 & $540($ s.d. $=39)$ & 1.06 & 5.98 \\
95 & $313($ s.d. $=15)$ & 1.06 & 6.07 \\
\hline
\end{tabular}

* standard deviation

** sintered density 
aが注汪 0 となった時点，すなわちフロックが消隇し， ほぼ100\%造粒体となったあとでは，造粒体の粒度分布 幅はきわめて狭くなり，造粒体の球形度は急速に低下し 真球に近づく。架橋液体添加量の造粒体径等におよぼ す影響については, 先の研究結果 $6,8,9)$ と同様であった。

Fig. 4 亿 Fig. 3 の実験で造粒終了10秒前に計測した それぞれのノイズの波形を示す。机，同図中にその とさの相対エネルギー值 $\left(E_{r}\right)$ を表示した。架橋液体添 加量の低下に伴い, 振幅の大きな波が現机る頻度が増 光相対エネルギー值が高くなっていることがわかる。 架橋液体添加量の低下は, Table 1 からわかるよらに 造粒体径の低下，すなわち造粒体数の堌加を意味して いる。したがって, Fig. 3 亿おいて，造粒経過時にお けるイベント発生率および相対エネルギ一值の増大は, 造粒体之造粒容器内壁々の衝突回数の増加に伴う衝突 波放出回数の増加と, その祭の衝突エネルギーの増加
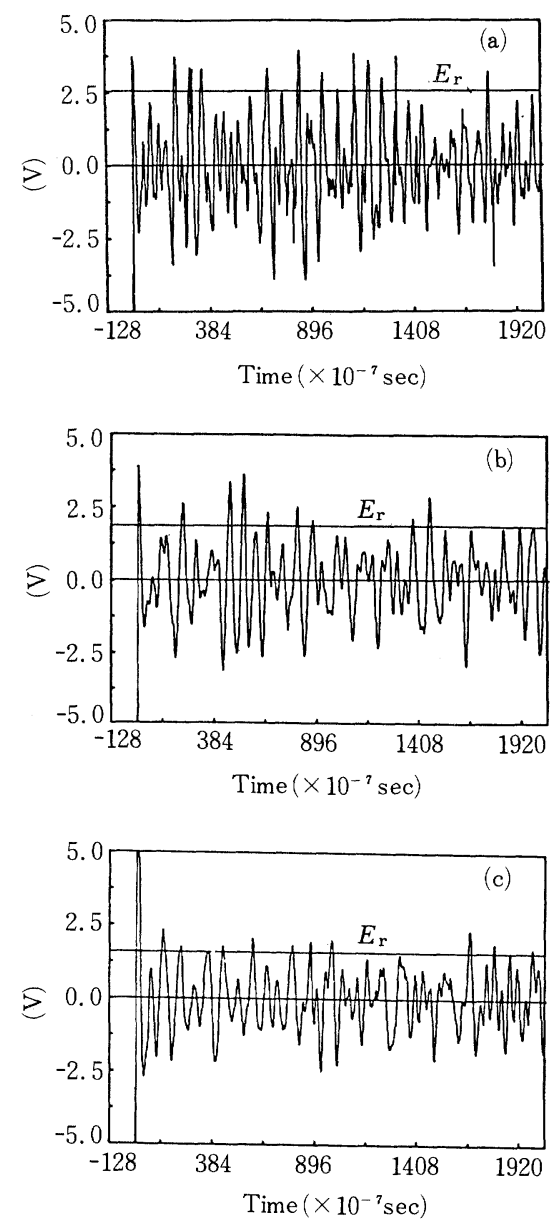

Fig. 4 Typical noise waveforms with corresponding relative energy for different amounts of bridging liquid : (a) 95 , (b) 105 and (c) $115 \mathrm{~cm}^{3} / \mathrm{kg}$
を指示していると考穴られる。

この観点に立脚して, 架橋液体添加量95, 105, 115 $\mathrm{cm}^{3} / \mathrm{kg}$ の条件下で造粒時間を変化させ油中造粒実験を 行い, 相対エネルギー値 $\left(E_{r}\right)$ と造粒体平均径 $\left(D_{50}\right)$ 和 よび回収率 $(R)$ との関係について検討を行った。その 結果，これらの間には，次の関係が成立した。

$$
E_{r}=49.6 D_{50}^{-0.729} R^{0.285}
$$

Fig. 5 に， $D_{50}$ と $R$ の実測值をEq. (2) 亿代入し求め た $E_{r}$ (calc.) と実測された $E_{r}$ (meas.)との関係を示す。 両者の間には, 注ぼ 1 対 1 の対応関係が認められる。

Eq. (2)の関係が，一定の密度 $(\rho)$ 拈よび粒径 $(D)$ を 有する球形造粒体についても成立すると仮定し， $D$ 之 造粒体数 $(N)$ が $E_{r}$ におよ活す影響について調べた。

$R$ は，次式で与えられる。

$$
\begin{aligned}
R & =W_{a} / W \times 100 \\
& =\frac{\pi \rho D^{3} N}{6 W} \times 100
\end{aligned}
$$

ここに,Wはフィード試料重量, $W_{a}$ は造粒体の全重 量である。Eqs. (2), (3) より， $E_{r}$ と $D$ おひび $N$ との 間には次の関係が得られる。

$$
E_{r} \propto D^{0.126} N^{0.285}
$$

$E_{r}$ は, Dが一定であれば $N$ の増加に伴い増大し， $N$ が一定であればDの増大に伴い増大寸る。 $E_{r} か ゙ D と N$ に依存するといら関係は，模擬造粒体としてガラスビ

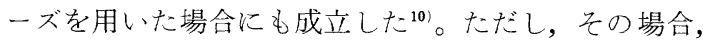
$E_{r}$ は $D$ の約 3 乗に比例しており，ガラスビーズでは, 造粒体に比べ粒子径の影響を強く受けることがわかっ た。このことは，造粒体が塑性的であるのに対しガラ スビーズがより弾性的であることに，主に起因してい ると考光られる。

$\mathrm{Eq} \cdot(2)$ より， $D_{50}$ と $E_{r}$ およびRとの関係は次式で与 光らる。

$$
D_{50}=\left(49.6 \frac{R^{0.285}}{E_{r}}\right)^{1.37}
$$

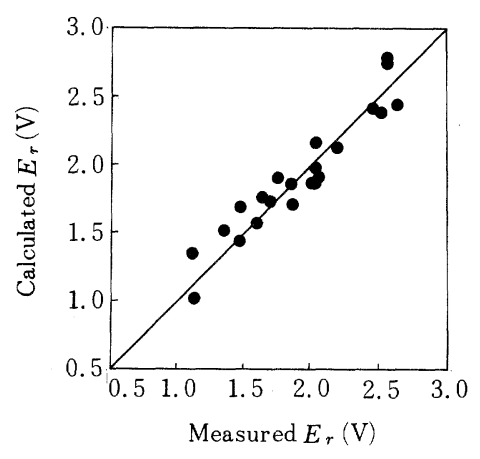

Fig. 5 Comparison of measured and calculated relative energy 


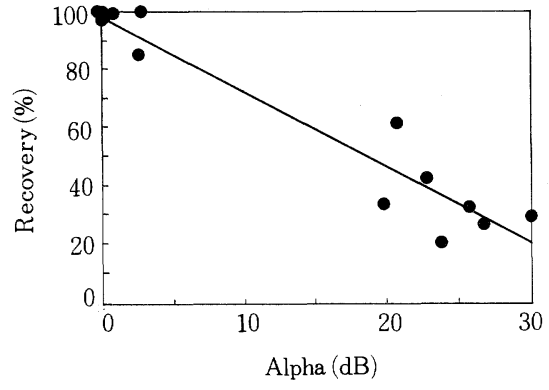

Fig. 6 Correlation of $\alpha$ and recovery

造粒実験で得られた $\alpha$ と $R$ と関係を, Fig. 6 亿示 す。両者の関係は, ほぼ直線で近似でき，それらの関 係は次式で与兄られる。

$$
R=99.4-2.60 \alpha
$$

Eqs. (5)，(6) より， $D_{50}$ は次式で表される。

$$
D_{50}=\left(49.6 \frac{(99.4-2.60 \alpha)^{0.285}}{E_{r}}\right)^{1.37}
$$

$\alpha$ とErをオンライン計測し, Eqs. (6), (7) に代入す ることによりRおよび $D_{50}$ のモニタリングが可能になる。

Fig. 7 亿 Fig. 3 の計測結果を基に求めた $D_{50}$ 拈よび
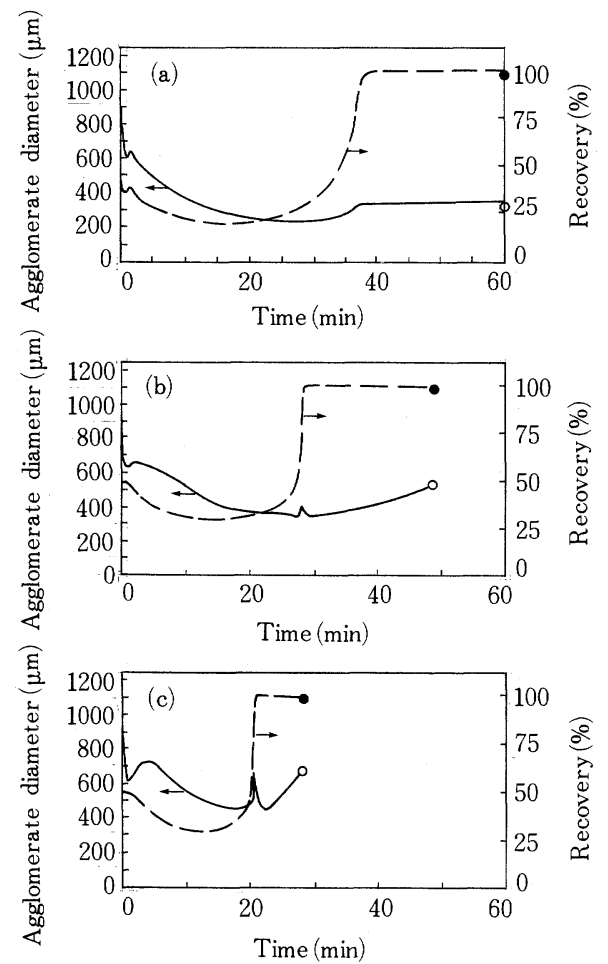

Fig. 7 Calculated recovery and agglomerate diameter as a function of lapse of time for different amounts of bridging liquid : (a) 95, (b) 105 and (c) 115 $\mathrm{cm}^{3} / \mathrm{kg}$. Measured values are indicated by marks $\bigcirc$ and
$R$ の経時変化を示す。なお，造粒終了時のそれらの実 測値を図中に示してある。架橋液体添加量95, 105, 115 $\mathrm{cm}^{3} / \mathrm{kg}$ いずれの場合も造粒開始直後に造粒体径の減小 が認められる。本実験では，擋拌開始前に架橋液体を 添加している。このため沈降しているジルコニア試料 の一部は，架橋液体によりペースト状態となっており， 擋拌開始直後には，このペースト状態の産物の破壊が 起こっていると推察される。架橋液体添加量 $115 \mathrm{~cm}^{3}$ / kgの場合には，回収率が急激に増加するに伴い造粒体 の急速な成長が認められ，その直後に造粒体の破壊が 起こっている。このことが，Fig. 3 で $\alpha$ が 0 となる付 近で認められた相対エネルギー，イベント発生率の一 時的な変動の原因である。この現象は, 架橋液体添加 量の低下に伴い顕著には認められなくなる。

Fig. 8 亿架橋液体添加量 $115 \mathrm{~cm}^{3} / \mathrm{kg}$ として造粒時間 を変化させた場合の $\alpha$ ，相対エネルギー，イベント発 生率の経時変化を，Fig. 9 にFig. 8 の $\alpha$ および相対工 ネルギーより求めた $D_{50}$ および $R$ 経時変化を示す。計
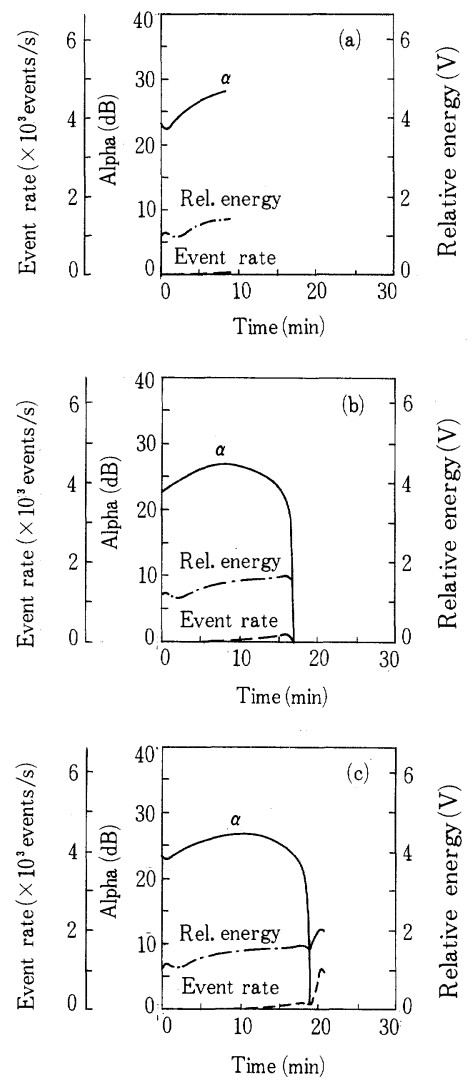

Fig. 8 Variation of $\alpha$, event rate and relative energy with lapse of time : (a) 9, (b) 18 and (c) $20 \mathrm{~min}$. Amount of bridging liquid $=115 \mathrm{~cm}^{3} / \mathrm{kg}$ 

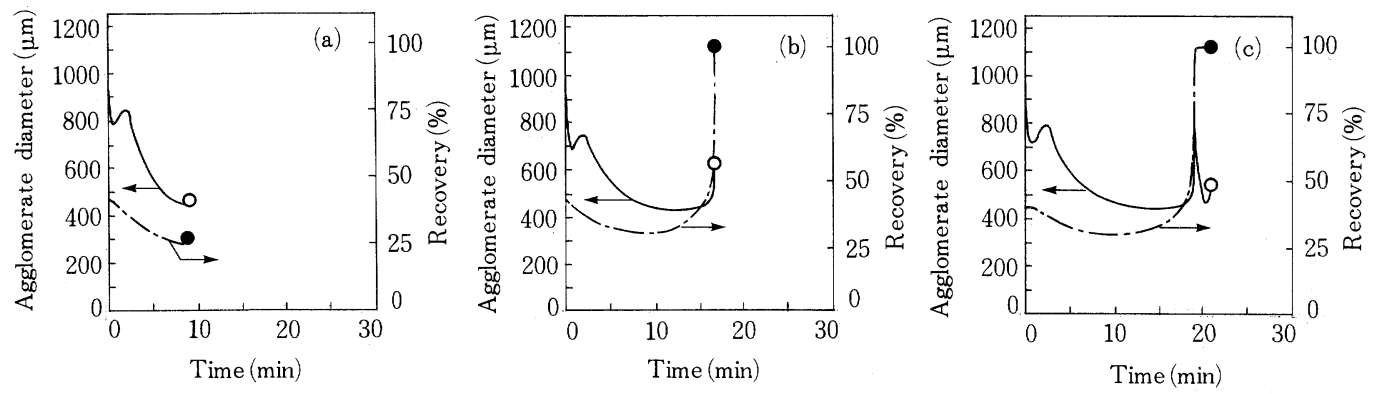

Fig. 9 Calculated recovery and agglomerate diameter as a function of lapse of time : (a) 9, (b) 18 and (c) 20 min. Amount of bridging liquid $=115 \mathrm{~cm}^{3} / \mathrm{kg}$. Measured values are indicated by marks $\bigcirc$ and

算結果と造粒終了時のそれらの実測值とは良く一致し ており，本法により造粒体平均径および回収率のオン ラインモニタリングが可能であることがわかる。

\section{4. 結言}

油中造粒過程で発生するノイズ括よび懸濁液の濁度

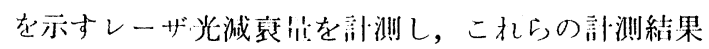
に基ついてオンラインで造粒体の回収率，造粒体径を

$$
\begin{aligned}
& \text { モニタリングする方法について検討した。 } \\
& \text { 油中造粒過程で発生する,イズの相対エネルギーは, } \\
& \text { 造粒体平均径と回収率に依存することを明らかにした。 } \\
& \text { 造粒体の回収率は, レーザ光減衰量より求められた。 } \\
& \text { これらの結果から,レーザ光減衰最と相対エネルギ } \\
& \text { 一をオンライン計測することにより, 造粒体平均径お } \\
& \text { よび回収率のオンラインモニタリングが可能であるこ } \\
& \text { とを示した。 }
\end{aligned}
$$

\section{Nomenclature}

$D \quad$ : agglomerate diameter

$D_{50}$ : mean agglomerate diameter

$E_{r} \quad$ : relative energy

$I \quad$ : intensity of laser beam after attenuation caused by particles

$I_{0} \quad$ : intensity of laser beam without attenuation caused by particles (i m) $\quad N \quad$ : number of agglomerates

( $\mu \mathrm{m}) \quad R \quad$ : recovery given by Eq. (3)

(V)
$W \quad$ : weight of feed powder

$W_{a} \quad$ : total weight of agglomerates

$\alpha \quad$ : attenuation given by Eq. (1)

$\rho \quad$ : agglomerate density
$(-)$

$\left(\mathrm{kg} / \mathrm{m}^{3}\right)$

\section{References}

1) Hirajima, T., T. Takamori, M. Tsunekawa, W. Guinto and M. Nakamura : Preprint of Annual Meet. of Min. Mat. Proc. Inst. Japan, 297 (1989)

2) Takamori, T., T. Hirajima, W. Guinto, M. Tsunekawa, F. Saga and M. Nakamura : Proc. 2nd World Congress Particle Technology, p.630 Soc. of Powder Technol., Japan(1990)

3) Guinto, W., T. Hirajima, T. Takamori, M. Tsunekawa and M. Nakamura : Hokkaido Geotechnics, No. 2, 19(1991)

4) Nakamura, M. : Funtai to Kogyo, 23, 37(1991)

5) Takamori, T., T. Hirajima, M. Tsunekawa and A. Otsuka : Powder Technology, Ed. by Iinoya, K., J.
K. Beddow and G. Jimbo, p. 656, Hemisphere (1984)

6) Hirajima, T., M. Tsunekawa, T. Takamori : J. Min. and Mat. Proc. Inst. Japan, 108, 146(1992)

7) Yoshida, Y., M. Tsunekawa, A. Nishitsuji, and S. Kinoshita : J. Soc. Powder Technol., Japan, 25, 621 (1988)

8) Hirajima, T., M. Tsurui and T. Takamori : J. Min. and Met. Inst. Japan, 98, 1243(1982)

9) Hirajima, T., T. Takamori, M. Tsunekawa and M. Tsuri : J. Min. and Met. Inst. Japan, 103, 577 (1987)

10) Guinto, W. et al. : to be published 